\title{
Pretreatment with Monosialoganglioside GM1 Protects the Brain of Fetal Sheep against Hypoxic-Ischemic Injury without Causing Systemic Compromise
}

\author{
WILliAM K. M. TAN, CHRIS E. WILLIAMS, ALISTAIR J. GUNN, E. CARINA MALLARD, AND \\ PETER D. GLUCKMAN \\ Research Centre for Developmental Medicine and Biology, School of Medicine, University of Auckland, \\ Auckland, New Zealand
}

\begin{abstract}
The purpose of this study was to determine whether prophylaxis with monosialoganglioside GM1 can protect the fetus from hypoxic-ischemic encephalopathy in utero. Because some protective strategies can compromise the fetus, the effect of GM1 treatment on metabolic status and blood pressure was also evaluated. Chronically instrumented near-term fetal sheep (119-133 d) were subjected to $\mathbf{3 0} \mathrm{min}$ of severe cerebral ischemia. Six were given $\mathbf{3 0}$ $\mathrm{mg} / \mathrm{kg}$ GM1 through the umbilical vein $2 \mathrm{~h}$ before insult followed by continuous infusion of $30 \mathrm{mg} / \mathrm{kg} / \mathrm{d}$ over the next $60 \mathrm{~h}$, and these were compared with seven vehicletreated control sheep. The time course of electrocorticographic activity and cytotoxic edema within the parasagittal cortex were determined with real-time spectral analysis and continuous impedance measurements, respectively. Histologic outcome was assessed 72 h later. Pretreatment with GM1 improved recovery of primary edema, reduced the duration of epileptiform activity $(15 \pm 2$ versus $31 \pm 5$ $\mathrm{h} ; p<0.05)$ and the magnitude of secondary edema $(p<$ $0.05)$. At $72 \mathrm{~h}$, histologic damage was reduced, particularly in the cortex $(p<0.05)$ and hippocampus $(p<0.01)$, and residual electrocorticographic activity was increased in the GM1-treated group $(-5 \pm 1$ versus $-9 \pm 3 \mathrm{~dB}, p<0.01)$. GM1 infusion did not alter arterial blood pressure or metabolic status. These results indicate that GM1 can protect the fetal brain against hypoxic-ischemic injury without causing hypotension or metabolic compromise. (Pediatr Res 34: 18-22, 1993)
\end{abstract}

\section{Abbreviations}

HI, hypoxic-ischemic

ECoG, electrocorticographic

EAA, excitatory amino acid

A number of strategies have been suggested to protect the CNS against $\mathrm{HI}$ injury. This range of approaches reflects the multiplicity of neurotoxic processes initiated by such insult. Particular attention has focused on the use of calcium channel antagonists,

Received September 9, 1992; accepted February 8, 1993.

Correspondence: Dr. C. E. Williams, Research Centre for Developmental Medicine and Biology, School of Medicine, University of Auckland, Private Bag, Auckland, New Zealand.

Supported by grants from the Health Research Council of New Zealand, the Neurological Foundation, and the National Children's Health Research Foundation of New Zealand. W.K.M.T. was supported by a Tan Kah Kee Foundation Postgraduate Scholarship, Singapore. glutamate antagonists, and free radical scavengers. However, the potential application of many proposed treatments in the perinatal period is limited. For example, calcium channel antagonists, although neuroprotective, can cause hypotension and compound the injury (1-3). Glutamate antagonists can have a number of side effects $(4,5)$. Increasingly, it is recognized that perinatal asphyxial encephalopathy can originate from prenatal insults (6-9). Although urgent delivery and postasphyxial approaches to therapy may well be the mainstay of obstetric management, the potential for intrauterine prophylaxis of the fetus at risk while awaiting delivery should not be ignored.

The gangliosides are a family of glycosphingolipids that are endogenous components of plasma membrane. Exogenous monosialoganglioside GM1 has been shown to be neuroprotective $(10-14)$ and can cross the placenta (15). We recently described an experimental preparation in which a chronically instrumented fetal sheep is subjected to transient cerebral ischemia; this procedure induces an encephalopathy showing characteristics similar to HI brain damage of some asphyxiated term infants (16). We have used this preparation to examine whether GM1 is neuroprotective in utero and whether it causes hypotension or compromises metabolic status.

\section{MATERIALS AND METHODS}

Surgical procedures. Nineteen Romney/Suffolk fetal sheep from 119 to $133 \mathrm{~d}$ of gestation were operated on under halothane anesthesia (2\%) using sterile techniques as previously described (16). Briefly, the head, neck, and forelimbs of the fetus were externalized and catheters were inserted into the ascending aortic arteries, umbilical vein, brachial vein, and amniotic cavity. Three pairs of shielded stainless steel electrodes were placed over the parietal dura, two at $10 \mathrm{~mm}$ lateral to the bregma and $5 \mathrm{~mm}$ and $15 \mathrm{~mm}$ anterior, and the third at $15 \mathrm{~mm}$ lateral and $10 \mathrm{~mm}$ anterior to the bregma. A pair of electrodes was also sewn into the paraspinal nuchal muscle to record electromyographic activity. The vertebral-occipital anastomoses between the carotid arteries and vertebral arteries were ligated bilaterally to eliminate vertebral blood supply to the brain. Inflatable occluder cuffs were placed around both carotid arteries. The fetus was returned to the uterus and the uterine and abdominal walls were closed. After the operation, the ewe was housed in a metabolic cage at constant temperature $\left(20^{\circ} \mathrm{C}\right)$ and humidity $(50 \%)$ and given free access to hay and water, supplemented by sheep nuts and alfalfa. Antibiotics (gentamicin, $80 \mathrm{mg}$; penicillin, $500 \mathrm{mg}$ ) were administered to the ewe daily.

Recordings. A four-electrode technique was used to measure changes in impedance associated with changes in extracellular space that occur concomitantly with cytotoxic edema (17). The 
impedance signal, ECoG, nuchal electromyographic, and fetal arterial blood pressure corrected for amniotic fluid pressure were recorded on an analog chart running at $5 \mathrm{~mm} / \mathrm{min}$. ECoG intensity spectra were analyzed on-line as previously described (16).

Experimental procedures. Experiments were performed $72 \mathrm{~h}$ after surgery. Fetal arterial samples were obtained before the start of each experiment and only fetuses with normal arterial blood gases $(\mathrm{pH}>7.32$ and arterial oxygen pressure $>2.26 \mathrm{kPa}$ ) were used. After a baseline recording period of $12 \mathrm{~h}$, the carotid cuffs were inflated with saline solution for $30 \mathrm{~min}$. Successful occlusion was confirmed by an isoelectric ECoG. Six animals were rejected from the analysis, four due to poor baseline arterial blood gases and two (one was infused with GMI and the other was a vehicletreated control) due to incomplete suppression of the ECoG during occlusion presumably reflecting inadequate ligation of the vertebral-occipital anastomoses. Animals were assigned to two groups, with one group receiving GM1 (Fidia Research Laboratories, Abano Terme, Italy) $(n=6)$ and the control group $(n=7)$ receiving equivalent volumes of phosphate buffer infusion only. In the former group, $30 \mathrm{mg} / \mathrm{kg}$ of GMI dissolved in phosphate buffer ( $\mathrm{pH}=7.4$ ) was administered systemically through the umbilical vein as a bolus $2 \mathrm{~h}$ before the ischemia followed by a continuous infusion of $30 \mathrm{mg} / \mathrm{kg} / \mathrm{d}$ administered at a rate of $1.2 \mathrm{~mL} / \mathrm{h}$ using a syringe pump (Harvard Apparatus, Millis, MA) over the next $60 \mathrm{~h}$ postinsult. These experiments were approved by the Animal Ethics Committee of the University of Auckland.

Histology. Each sheep was killed by pentobarbital injection 3 $\mathrm{d}$ after the ischemia. The fetal brain was immediately perfused through the carotid arteries with $500 \mathrm{~mL}$ of physiologic saline followed by $500 \mathrm{~mL}$ of FAM (formaldehyde, acetic acid, methanol; 1:1:8). The fixed brain was removed and placed in FAM for at least $24 \mathrm{~h}$. After processing and wax-embedding in paraffin, coronal subserial sections were cut $8 \mu \mathrm{m}$ thick and then stained with thionin-acid fuchsin (18). Every 40th section was examined by light microscopy by two independent assessors, one of whom was blinded to the experiment. The correlation coefficient between scores obtained by the two observers was $0.88(p<0.01)$. Neurons with ischemic cell change, consisting of acidophilic (red) cytoplasm and contracted nuclei or with just a thin rim of red cytoplasm with pyknotic nuclei, were assessed as dead, whereas all others were considered viable (19). Each region was scored for the proportion of dead neurons as follows: $0=$ no dead neurons, $5=0$ to $10 \%, 30=10$ to $50 \%, 70=50$ to $90 \%, 95=$ 90 to $99 \%$, and $100=100 \%$. Each score corresponds with the midpoint of its range (16).

Analysis. The ECoG intensity was presented in $\mathrm{dB}[\log (\mathrm{x}) \cdot 10]$ because this transformation gives a better approximation to the normal distribution (20). The intensity was then normalized with respect to the 12-h reference period before occlusion; thus, these measurements are expressed as a log ratio of the baseline period. A digital Blackman low-pass filter with a cutoff of 0.1 cycles/ point was applied to the log-transformed ECoG intensity data to minimize short-term fluctuations of less than $20 \mathrm{~min}$. Similarly, a cutoff of 0.25 cycles/point was applied to the impedance time series. The final ECoG intensity was calculated as the average of the final $4-\mathrm{h}$ period, from 68 to $72 \mathrm{~h}$. The duration of the depressed period was measured as the time after insult that the ECoG was more than $8 \mathrm{~dB}$ below the baseline intensity. The onset of epileptiform activity was defined as the time after insult when smoothed ECoG intensity increased above $-5 \mathrm{~dB}$ of the preocclusion intensity, which corresponds to the development of low median frequency spike-wave or polyspike activity (21). We have previously shown that this activity is associated with electromyographic evidence of seizure activity (16). The impedance was expressed as a percentage of baseline levels and reflects changes in extracellular space (17). Onset of the acute and delayed increase in impedance was determined by the $10 \%$ rise above baseline. The time course of ECoG intensity and imped- ance in the two groups and arterial blood pressure before and during GMl infusion were compared using two-way analysis of variance with time as a repeated measure, followed by unpaired $t$ tests with Bonferroni's correction for multiple comparisons. All results are presented as mean \pm SEM.

Changes in histologic outcome were then compared by twoway analysis of variance with regions as a repeated measure and then by $t$ test with Bonferroni's correction for comparisons of the degrees of damage in the different regions.

\section{RESULTS}

The gestational age and physiologic parameters before insult were similar for the treatment and control groups (Table 1). During GM 1 infusion, there was no significant change in arterial blood pressure or alteration in the metabolic parameters compared with the controls (Table 1).

Thirty min of bilateral carotid occlusion induced complete suppression of the ECoG during ischemia (Fig. 1). The drop in ECoG intensity was not significantly different between the treated $(-12.4 \pm 1.8 \mathrm{~dB})$ and control $(-13.3 \pm 1.9 \mathrm{~dB})$ animals. The ECoG remained depressed after the insult. GM1-treated fetuses showed earlier recovery of ECoG intensity to $-8 \mathrm{~dB}(4.8$ $\pm 0.7 \mathrm{~h})$ than controls $(8.5 \pm 1.1 \mathrm{~h}, p<0.05)$. In both groups of animals, ECoG then progressively increased in intensity (Figs. 1 and 2). This was followed by a shift to a state of low median frequency epileptiform activity that corresponded with spikewave or polyspike activity on the raw ECoG and increased nuchal muscle activity (Fig. 3). The duration of epileptiform activity was shorter in the treated group $(15 \pm 2 \mathrm{~h})$ than in the controls $(31 \pm 5 \mathrm{~h}, p<0.05)$, although the peak and onset time of the epileptiform activity were not significantly different. From 10 to $30 \mathrm{~h}$ after ischemia, the ECoG of treated animals showed a significantly higher median frequency of $10.1 \pm 0.3 \mathrm{~Hz}$ compared with controls $(8.8 \pm 0.5 \mathrm{~Hz}, p<0.05)$. At $72 \mathrm{~h}$ after ischemia was induced, the residual ECoG intensity of GM1-treated fetuses was higher $(-5 \pm 1 \mathrm{~dB})$ than that of the controls $(-9 \pm 3 \mathrm{~dB}, p$ $<0.01$ ).

Cortical impedance rapidly increased from $5 \pm 2 \mathrm{~min}$ after occlusion and peaked at $3 \pm 2 \mathrm{~min}$ after release of the clamps (Fig. 1). The initial peak of impedance in the treated group $(144.3 \pm 5.5 \%)$, which was not significantly different from that in the controls $(143.6 \pm 4.7 \%, p=0.92)$, partially resolved with some residual impedance after the insult (Fig. 4). At $3 \mathrm{~h}$ after ischemia, the residual impedance was greater in the controls $(105.1 \pm 0.7 \%)$ than in the treatment group $(101.0 \pm 1.4 \%, p<$ $0.01)$. There was a secondary rise in impedance coincident with the onset of epileptiform activity (Figs. 1 and 2). The secondary increase in impedance in the controls occurred earlier (10\% rise at $8.9 \pm 0.6 \mathrm{~h})$ than that in the treated animals $(13.9 \pm 1.9 \mathrm{~h}, p$ $<0.05)$ and gradually reached a peak of $133.1 \pm 5.1 \%$ in the former as compared with $118.2 \pm 3.4 \%(p<0.05)$ in the latter group, although the secondary peak occurred at a similar time $(36.9 \pm 3.8 \mathrm{~h})$. The residual increase in impedance at $72 \mathrm{~h}$ was lower in the treated group $(105.5 \pm 1.9 \%)$ than in the controls $(120.3 \pm 4.7 \%, p<0.05)$.

There was an overall reduction in neuronal loss in the treated animals $(p<0.05)$ with greater improvement $(p<0.01)$ in the lateral (temporal) cortex and CA4 subfield of the hippocampus. Relative protection was conferred $(p<0.05)$ in the parasagittal cortex, thalamus, and the dentate gyrus, CA1, 2, and 3 regions of the hippocampus (Fig. 5).

\section{DISCUSSION}

HI encephalopathy in the fetal or perinatal period is believed to be an important cause of stillbirth and frequently leads to neurologic sequelae including cerebral palsy, sensory deficits, and learning disorders. Our study demonstrates that GM1 improved outcome as indicated by reduced neuronal loss, particu- 
Table 1. Changes in fetal blood pressure and metabolic status in response to infusion*

\begin{tabular}{|c|c|c|c|c|}
\hline & \multicolumn{2}{|c|}{$\begin{array}{c}\text { Vehicle-treated controls } \\
(n=7, \text { gestation }=125 \pm 3 \mathrm{~d})\end{array}$} & \multicolumn{2}{|c|}{$\begin{array}{c}\text { GMl-treated fetuses } \\
(n=6, \text { gestation }=126 \pm 2 \mathrm{~d})\end{array}$} \\
\hline & Baseline & Infusion & Baseline & Infusion \\
\hline $\mathrm{BP}(\mathrm{kPa})$ & $6.2 \pm 0.5$ & $6.1 \pm 0.5$ & $6.0 \pm 0.8$ & $6.1 \pm 0.8$ \\
\hline $\mathrm{pH}$ & $7.38 \pm 0.01$ & $7.36 \pm 0.01$ & $7.37 \pm 0.01$ & $7.36 \pm 0.01$ \\
\hline $\mathrm{PaO}_{2}(\mathrm{kPa})$ & $2.93 \pm 0.16$ & $2.75 \pm 0.15$ & $3.01 \pm 0.17$ & $2.98 \pm 0.18$ \\
\hline $\mathrm{PaCO}_{2}(\mathrm{kPa})$ & $6.18 \pm 0.27$ & $6.48 \pm 0.22$ & $6.51 \pm 0.23$ & $6.56 \pm 0.23$ \\
\hline Lactate $(\mathrm{mmol} / \mathrm{L})$ & $0.9 \pm 0.2$ & $1.0 \pm 0.1$ & $1.0 \pm 0.2$ & $1.0 \pm 0.1$ \\
\hline Glucose $(\mathrm{mmol} / \mathrm{L})$ & $0.9 \pm 0.1$ & $1.0 \pm 0.1$ & $0.9 \pm 0.1$ & $0.9 \pm 0.1$ \\
\hline
\end{tabular}

* Mean \pm SEM. Baseline $=2$-h period before any intervention. Infusion $=2$-h period before occlusion. $\mathrm{BP}$, blood pressure; PaO ${ }_{2}$, arterial oxygen pressure; $\mathrm{PaCO}_{2}$, arterial carbon dioxide pressure.
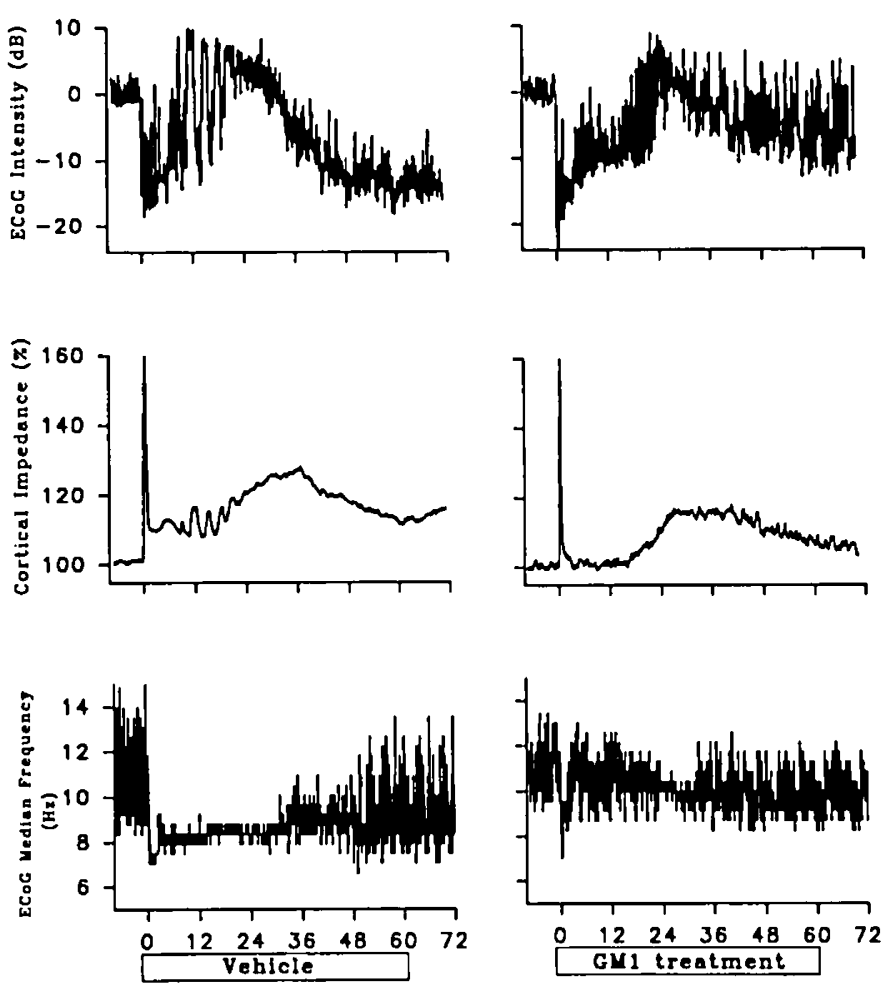

Time (hours)

Fig. 1. Time course of changes in ECoG intensity (upper panels), cortical impedance (middle panels), and ECoG median frequency (lower panels) in a representative GMl-treated fetal sheep (right) and a control animal (left) after $30 \mathrm{~min}$ of cerebral ischemia. GM1 $(30 \mathrm{mg} / \mathrm{kg})$ was given $2 \mathrm{~h}$ before the insult and continuously $(30 \mathrm{mg} / \mathrm{kg} / \mathrm{d})$ for $60 \mathrm{~h}$ after ischemia. Time is shown as hours postischemia. Note that after depression of the ECoG after the insult, intense low-frequency epileptiform activity developed in both GM1-treated and control animals. GM1 treatment improved recovery of primary edema and reduced the duration of epileptiform activity and magnitude of secondary edema. At $72 \mathrm{~h}$, residual ECoG intensity was higher in the GM1-treated group.

larly in the cortex and hippocampus, and greater residual ECoG activity. GMl therapy may therefore confer worthwhile in utero neuroprotection of the fetus against asphyxial insults.

Our findings are consistent with previous reports in adult animals demonstrating that systemic GM1 treatment can reduce morphologic, biochemical, neurophysiologic, and behavioral manifestations of HI brain damage (22-28). However, the concept of in utero neuroprotection has not been extensively considered. In the fetal rat subjected to umbilical cord occlusion, prophylactic maternal administration of nimodipine reduces postnatal histochemical derangement and behavioral impairment (29). Previous studies have reported that treatment with the calcium channel antagonists nicardipine or flunarizine can cause cardiac depression and death at high doses in fetal sheep
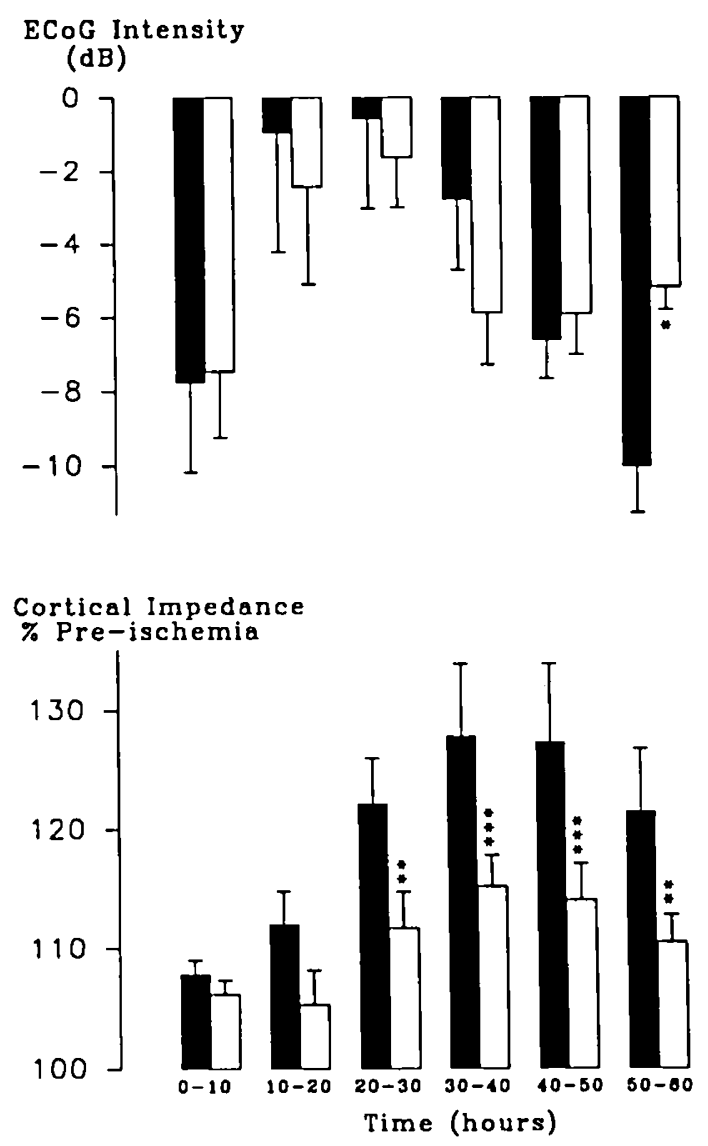

Fig. 2. Bar graphs comparing the time course of changes in mean ECoG intensity (upper panel) and mean cortical impedance (lower panel) after $30 \mathrm{~min}$ of cerebral ischemia in GMl-treated fetuses (white bars) and vehicle-controls (black bars). GM1 $(30 \mathrm{mg} / \mathrm{kg}$ ) was given $2 \mathrm{~h}$ before the insult and continuously $(30 \mathrm{mg} / \mathrm{kg} / \mathrm{d})$ for $60 \mathrm{~h}$ after ischemia. Onset of the secondary increase in impedance coincided with the onset of epileptiform activity. Time is shown as hours postischemia. ${ }^{*}, p<0.05$; ${ }^{* *}, p<0.01{ }^{* * *}, p<0.001$ (repeated-measures analysis of variance).

$(1,2)$ or human neonates $(3)$. Our data showed that GM1 did not alter fetal arterial blood pressure or metabolic status and confirmed previous findings in adults (30) supporting the potential application of this agent.

GM1-treated fetuses in our study showed less residual cytotoxic edema after ischemia. This suggests that neuroprotection is conferred during the acute phase of the ischemic injury and reperfusion. This early action in the cascade of events responsible for neuronal damage may account for the subsequent delay in the onset and magnitude of secondary edema and the shorter duration of low-frequency epileptiform activity, thereby resulting in greater ECoG intensity and improved histologic outcome at $72 \mathrm{~h}$ postischemia. Several mechanisms have been proposed to explain the capability of GM1 to limit neuronal damage associ- 
A

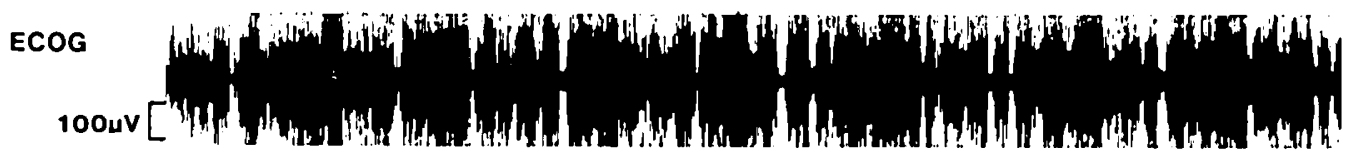
NUCHAL EMG

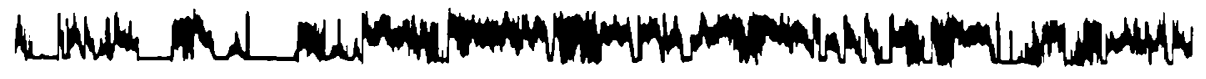

B

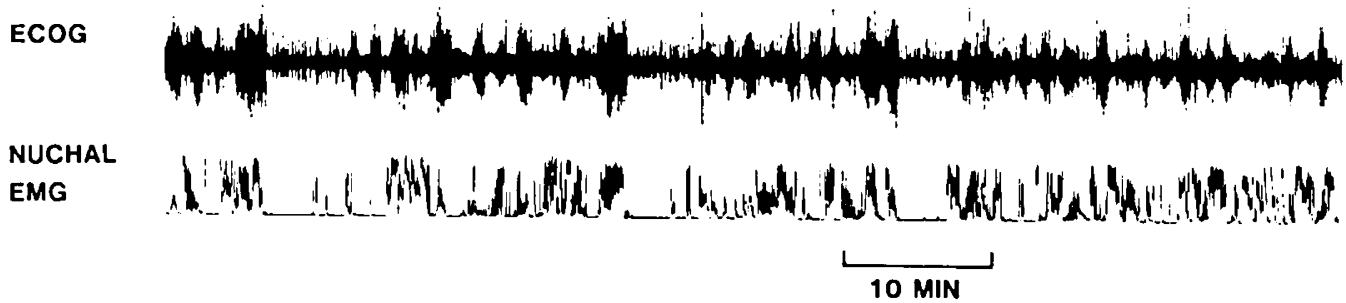

Fig. 3. Representative chart recordings showing raw ECoG and nuchal electromyographic $(E M G)$ activity from $10 \mathrm{~h}$ after insult in control $(A)$ and GM 1-treated $(B)$ animals. The intense low-frequency epileptiform activity was recorded as spike-wave or polyspike activity and increased nuchal activity. In $B$, GMI $(30 \mathrm{mg} / \mathrm{kg})$ was given at $2 \mathrm{~h}$ before the insult and continuously $(30 \mathrm{mg} / \mathrm{kg} / \mathrm{d})$ for $60 \mathrm{~h}$ after ischemia.

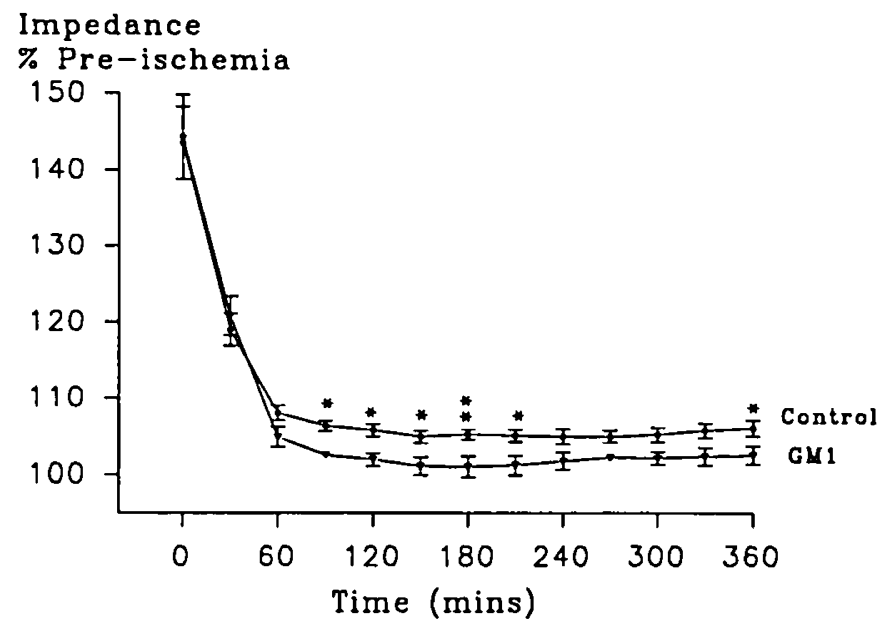

Fig. 4. Graph comparing the time course of change in impedance after $30 \mathrm{~min}$ of cerebral ischemia in control $(\bullet)$ and GM 1 -treated animals $(\nabla)$. The initial peak of impedance partially resolved with some residual impedance after the insult. The residual impedance was significantly greater in the controls than in the treatment group. Time is shown as hours postischemia. ${ }^{*}, p<0.05 ;{ }^{* *}, p<0.01$.

ated with cerebral $\mathrm{HI}$ insult. These include a direct membrane effect that involves incorporation of GMl into plasma membranes and results in a stabilization of structure and function. When added to cultured neuronal cells, GM1 is incorporated into the plasma membrane in a time- and concentration-dependent manner $(31,32)$. A similar uptake occurs in the CNS after the systemic administration of GMI in vivo (33). The reduction in losses of enzymes and fatty acids from plasma membranes (25) supports the hypothesis that GM1 has a direct role in the protection of membrane structure and function.

GMI can protect neurons against excitotoxicity. Studies have shown that GM1 attenuates EAA-related neurotoxicity in neuronal cell cultures (34-39). GM1, when administered systemically to neonatal or adult rodents, reduces brain neuronal damage induced by exogenous excitotoxins $(11,40,41)$. The antiexcitotoxic effects of GM1, unlike those of EAA antagonists, appear to occur by inhibition of intracellular toxic-related events resulting from excessive activation of EAA receptors (38, 42). GM1 was reported to inhibit glutamate-mediated translocation of protein kinase $\mathrm{C}$ from cytosol to cell membranes involved in $\mathrm{Ca}^{2+}$ influx, thereby limiting the increase in intracellular free $\mathrm{Ca}^{2+}$ in primary granular cerebellar cultures $(38,43,44)$ and in fetal rat

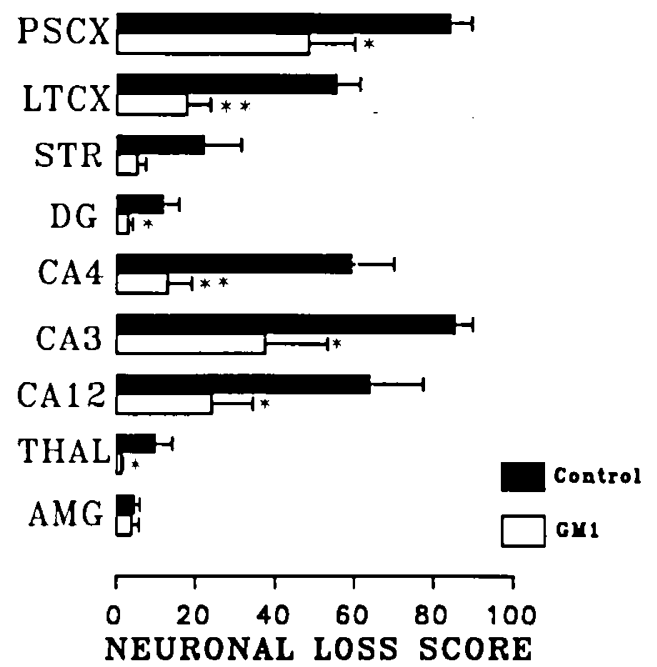

Fig. 5. Histologic demonstration of neuronal damage in various brain regions at $72 \mathrm{~h}$ after $30 \mathrm{~min}$ of cerebral ischemia. Damage scores are on a linearized scale, 0 to 100. 0: no neuronal loss; 100: total necrosis. Values are means \pm SEM. GM1-treated animals showed significantly less damage $(*, p<0.05)$. PSCX, parasagittal cortex; $L T C X$, lateral cortex; $S T R$, striatum; $D G$, dentate gyrus; $C A 12,3,4$, cornu ammonis $1,2,3$, and 4 of the hippocampus; $T H A L$, thalamus; $A M G$, amygdala.

brain (15). Alternatively, GM1 has been shown to potentiate the action of neuronotrophic factors both in vitro (45-47) and in vivo (47-50) that may improve the survival rate of injured neurons.

In summary, these observations suggest that pretreatment with GM1 protects the brain of fetal sheep during the acute phase of HI injury. GM1 can cross the placental barrier (15) and lacks systemic side effects that are observed with other potential prophylactic agents such as glutamate and calcium antagonists. Thus, prophylactic therapy in utero with GM1 is a potential strategy to protect the CNS of fetuses at risk of HI injury.

Acknowledgment. The authors thank Fidia Research Laboratories, Abano Terme, Italy for the gift of GM1.

\section{REFERENCES}

1. Jensen A, Klossek H 1990 Effects of flunarizine on fetal circulatory centralization during acute asphyxia in sheep. Society for the Study of Fetal Physiology, 17th International Meeting. Asilomar, CA. D-10(abstr) 
2. Gunn AJ, Tan WKM, Gluckman PD, Williams CE 1991 Neuroprotection of the fetus at risk of asphyxic injury. In: International Conference on Neuroprotective Agents, Rockland, ME, 1991

3. Levene MI, Gibson NA, Fenton AC, Papathoma E, Barnett D 1990 The use of a calcium channel blocker, nicardipine, for severely asphyxiated newborn infants. Dev Med Child Neurol 32:567-574

4. Morris RGM, Anderson E, Lynch GS, Baudry M 1986 Selective impairment of learning and blockade of long-term potentiation by an N-methyl-Daspartate receptor antagonist, APS. Nature 319:774-776

5. Olney JW, Labruyere J, Price MT 1989 Pathological changes induced in cerebrocortical neurons by phencyclidine and related drugs. Science 244:1360-1362

6. Scher MS, Belfar H, Martin J, Painter MJ 1991 Destructive brain lesions of presumed fetal onset: antepartum causes of cerebral palsy. Pediatrics 88:898906

7. Bejar R, Wozniak P, Allard M, Bernirschke K, Baucher Y 1988 Antenatal origin of neurologic damage in newborn infants. Am J Obstet Gynecol 159:357-363

8. Shields JR, Schifrin BS 1988 Perinatal antecedents of cerebral palsy. Obstet Gynecol 71:899-905

9. Paul R, Yonekura L, Cantrell C, Turkel S, Pablova Z, Sipos L 1986 Fetal injury prior to labor: does it happen? Am J Obstet Gynecol 154:1187-1193

10. Karpiak SE, Mahadik SP, Wakade CG 1990 Ganglioside reduction of ischemic injury. Crit Rev Neurobiol 5:221-237

11. Lipartiti M, Lazzaro A, Zanoni R, Bonvento G, Mazzari S 1991 Effects of monosialoganglioside GM 1 in experimental models of ischemic brain damage. Ital J Neurol Sci 12:11-13

12. Lipartiti M, Seren MS, Lazzaro A, Koga T, Mazzari S, Facci L, Fusco M, Toffano G, Leon A 1990 Monosialoganglioside effects following cerebral ischemia: relationship with anti-neuronotoxic and pro-neuronotrophic effects. Acta Neurobiol Exp (Warsz) 50:489-494

13. Leon A, Lipartiti M, Seren MS, Lazzaro A, Mazzari S, Koga T, Toffano G, Skaper SD 1990 Hypoxic-ischemic damage and the neuroprotective effects of GM1 ganglioside. Stroke 21:11195-III97

14. Carolei A, Fieschi C, Bruno R, Toffano G 1991 Monosialoganglioside GM 1 in cerebral ischemia. Cerebrovasc Brain Metab Rev 3:134-157

15. Magal E, Louis JC, Aguilera J, Yavin E 1990 Gangliosides prevent ischemiainduced down-regulation of protein kinase $\mathrm{C}$ in fetal rat brain. $\mathrm{J}$ Neurochem $55: 2126-2131$

16. Williams CE, Gunn AJ, Gluckman PD, Synek B 1990 Delayed seizures occurring with hypoxic-ischemic encephalopathy in the fetal sheep. Pediatr Res 27:561-565

17. Williams CE, Gunn AJ, Gluckman PD 1991 Time course of intracellular edema and epileptiform activity following prenatal cerebral ischemia in sheep. Stroke 22:516-521

18. Smith M, Auer RN, Siesjo BK 1984 The density and distribution of ischemic brain injury in the rat following $2-10 \mathrm{~min}$ of forebrain ischemia. Acta Neuropathol 64:319-332

19. Brown AW, Brierley JB 1972 Anoxic-ischaemic cell change in rat brain: light microscopic and fine structural observations. J Neurol Sci 16:59-84

20. Gasser T, Bacher P, Mocks J 1982 Transformations towards the normal distribution of broad band spectral parameters of the EEG. Electroencephalogr Clin Neurophysiol 53:119-124

21. Tan WKM, Williams CE, Gunn AJ, Mallard EC, Gluckman PD 1992 Suppression of post-ischemic epileptiform activity with MK-801 improves neural outcome in fetal sheep. Ann Neurol 32:677-682

22. Karpiak SE, Wakade CG, Tagliavia A, Mahadik SP 1991 Temporal changes in edema, $\mathrm{Na}^{+}, \mathrm{K}^{+}$, and $\mathrm{Ca}^{++}$in focal cortical stroke: GMl ganglioside reduces ischemic injury. J Neurosci Res 30:512-520

23. Bharucha VA, Wakade CG, Mahadik SP, Karpiak SE 1991 GMI ganglioside treatment reduces functional deficits associated with cortical focal ischemia. Exp Neurol 114:136-139

24. Ortiz A, MacDonall JS, Wakade CG, Karpiak SE 1990 GMI ganglioside reduces cognitive dysfunction after focal cortical ischemia. Pharmacol Biochem Behav 37:679-684

25. Mahadik SP, Hawver DB, Hungund BL, Li YS, Karpiak SE 1989 GM ganglioside treatment after global ischemia protects changes in membrane fatty acids and properties of $\mathrm{Na}^{+}, \mathrm{K}^{+}$-ATPase and $\mathrm{Mg}^{2+}$-ATPase. J Neurosci Res 24:402-412

26. Komatsumoto S, Greenberg JH, Hickey WF, Reivich M 1988 Effect of the ganglioside GMI on neurologic function, electroencephalogram amplitude, and histology in chronic middle cerebral artery occlusion in cats. Stroke 19:1027-1035

27. Cahn R, Borzeix MG, Aldinio C, Toffano G, Cahn J 1989 Influence of monosialoganglioside inner ester on neurologic recovery after global cerebral ischemia in monkeys. Stroke 20:652-656
28. Koga T, Kojima H, Yamada S, Miki K, Nishi S, Inanaga K, Shoji H, Kaji M, Jonsson G, Toffano G 1990 GMI ganglioside reduces edema and monoaminergic neuronal changes following experimental focal ischemia in rat brain. Brain Res 524:313-315

29. Shen Y, Isaacson RL, Smotherman WP 1991 The behavioral and anatomical effects of prenatal umbilical cord clamping in the rat and their alteration by the prior administration of nimodipine. Restor Neurol Neurosci 3:11-22

30. Greenberg JH, Reivich M, Urbanics R, Tanaka K, Dora E, Toffano G 1986 The effect of GMI on cerebral metabolism, microcirculation and histology in focal ischemia. In: Tettamanti G, Ledeen F, Sandhoff K, Nagai Y, Toffano G, (eds) Gangliosides and Neuronal Plasticity. Liviana Press, Padova, Italy, pp 396-405

31. Facci L, Leon A, Toffano G, Sonnino S, Ghidoni R, Tettamanti G 1984 Promotion of neuritogenesis in mouse neuroblastoma cells by exogenous gangliosides. Relationship between the effect and the cell association of ganglioside GM1. J Neurochem 42:299-305

32. Radzak K, Schwarzmann G, Wiegandt H 1982 Studies on the cell association of exogenously added sialoglycolipids. Hoppe Seylers Z Physiol Chem 263:243-272

33. Ghidoni R, Fiorilli A, Trinchera M, Venerando B, Chigorno V, Tettamanti G 1989 Uptake, cell penetration and metabolic processing of exogenously administered GMl ganglioside in rat brain. Neurochem Int 15:455-465

34. Skaper SD, Leon A, Facci L 1991 Death of cultured hippocampal pyramidal neurons induced by pathological activation of $\mathrm{N}$-methyl-D-aspartate receptors is reduced by monosialogangliosides. J Pharmacol Exp Ther 259:452-457

35. Skaper SD, Facci L, Leon A 1990 Gangliosides attenuate the delayed neurotoxicity of aspartic acid in vitro. Neurosci Lett 117:154-159

36. Facci L, Leon A, Skaper SD 1990 Hypoglycemic neurotoxicity in vitro involvement of excitatory amino acid receptors and attenuation by monosialoganglioside GM1. Neuroscience 37:709-716

37. Skaper SD, Facci L, Milani D, Leon A 1989 Monosialoganglioside GM protects against anoxia-induced neuronal death in vitro. Exp Neurol 106:297-305

38. Favaron $M$, Manev $H$, Alho $H$, Bertolino $M$, Ferret B, Guidotti A, Costa $E$ 1988 Gangliosides prevent glutamate and kainate neurotoxicity in primary neuronal cultures of neonatal rat cerebellum and cortex. Proc Natl Acad Sci USA 85:7351-7355

39. Manev H, Favaron M, Vicini S, Guidotti A, Costa E 1990 Glutamate-induced neuronal death in primary cultures of cerebellar granule cells: protection by synthetic derivatives of endogenous sphingolipids. J Pharmacol Exp Ther 252:419-427

40. Lipartiti M, Lazzaro A, Zanoni R, Mazzari S, Toffano G, Leon A 1991 Monosialoganglioside GMI reduces NMDA neurotoxicity in neonatal rat brain. Exp Neurol 113:301-305

41. Mahadik SP, Vilim F, Korenovsky A, Karpiak SE 1989 GM1 ganglioside acutely reduces excitotoxin damage in nucleus basalis: cortical cholinergic losses and mortality. J Neurosci Res 20:479-483

42. Manev H, Favaron M, Guidotti A, Costa E 1989 Delayed increase in $\mathrm{Ca}^{2+}$ influx elicited by glutamate: role in neuronal death. Mol Pharmacol 36:106112

43. Vaccarino F, Guidotti A, Costa E 1987 Ganglioside inhibition of glutamate mediated protein kinase $C$ translocation in primary cultures of cerebellar neurons. Proc Natl Acad Sci USA 84:8707-8711

44. Milani D, Guidolin D, Facci L, Pozzan T, Buso M, Leon A, Skaper SD 199 Excitatory amino acid-induced alterations of cytoplasmic free $\mathrm{Ca}^{2+}$ in individual cerebellar granule neurons: role in neurotoxicity. J Neurosci Res 28:434-441

45. Hilbush BS, Levine JM 1991 Stimulation of a $\mathrm{Ca}^{2+}$-dependent protein kinase by GM1 ganglioside in nerve growth factor-treated PC12 cells. Proc Natl Acad Sci USA 88:5616-5620

46. Spoerri PE, Roisen FJ 1988 Ganglioside potentiation of NGF-independent trophic agents on sensory ganglia. Neurosci Lett 90:21-26

47. Cuello AC, Garofalo L, Kenigsberg RL, Maysinger D 1989 Gangliosides potentiate in vivo and in vitro effects of nerve growth factor on central cholinergic neurons. Proc Natl Acad Sci USA 86:2056-2060

48. Casamenti F, Di Patre PL, Milan F, Petrelli L, Pepeu G 1989 Effects of nerve. growth factor and GM1 ganglioside on the number and size of cholinergic neurons in rats with unilateral lesion of the nucleus basalis. Neurosci Lett 103:87-91

49. Vantini G, Fusco M, Bigon E, Leon A 1988 GMl ganglioside potentiates the effects of nerve growth factor in preventing vinblastine-induced sympathectomy in newborn rats. Brain Res 448:252-258

50. Di Patre PL, Casamenti F, Cenni A, Pepeu G 1989 Interaction between nerve growth factor and GM1 monosialoganglioside in preventing cortical choline acetlyltransferase and high affinity choline uptake decrease after lesion of the nucleus basalis. Brain Res 480:219-224 